\title{
Optimal Environmental Policy Differentials in Open Economies under Emissions Constraints
}

\author{
C. A. Withagen, R. J. G. M. Florax and A. Mulatu \\ Received July 11, 2006; revised version received November 16, 2006 \\ Published online: March 22, 2007 \\ (C) Springer-Verlag 2007
}

Is there a case for preferential treatment of the exposed sector in an economy when compliance to an aggregate emissions constraint induced by an international environmental agreement is mandatory? This question is being debated in many countries in the context of the implementation of the Kyoto Protocol. We address the issue in a general equilibrium framework and theoretically cover several market structures, including perfect competition, the large country case and oligopoly. We identify the conditions under which preferential treatment of the exposed sector is not warranted from the point of view of maximizing social welfare. In addition, we demonstrate that in the case of oligopoly, instituting a more stringent environmental policy on the exposed sector might be profitenhancing for this sector. This finding lends theoretical support to a specific interpretation of the Porter hypothesis.

Keywords: ecological dumping, general equilibrium, emission constraint, Kyoto Protocol, Porter hypothesis.

JEL Classifications: D6, F12, Q28.

\section{Introduction}

The question whether governments have an incentive to implement an "over-lax" environmental policy for reasons of international competitiveness of the domestic industry, is one of the fundamental questions raised in the so-called "ecological dumping" literature. This literature specifically addresses the trade-off between increased competitiveness 
and increased pollution as a result of lax environmental taxation of the economy's exposed sector as compared to environmental taxes in the sheltered sector. Several related issues are being dealt with in the trade environment literature as well. For instance, the recent literature covers concerns such as free trade potentially causing more pollution, the existence of pollution havens, and environmental policy inducing capital flight (see, e.g., Ulph, 1999; and Copeland and Taylor, 2003).

The theoretical results with regard to ecological dumping depend largely on the market structures that are being studied. In the case of perfect competition on world markets and the absence of international spillovers, ecological dumping is sub-optimal from a social welfare perspective when taking into account the pollution damages (Rauscher, 1994; Neary, 2006). Hoel (1994) shows that differential treatment of domestic sectors can be justified, in particular if trade policy is impossible and transboundary pollution occurs. Rauscher (1994) suggests that in the case of a large country it may be optimal to implement a more stringent environmental policy on the exporting sector in order to improve the terms of trade.

The literature on optimal environmental policy in an oligopolistic world market is based on the strategic trade literature pioneered by Spencer and Brander (1983), and Brander and Spencer (1985). The core issue is whether welfare can be enhanced by changing the supply of the export industry in the home country, given a supply reaction function of foreign firms. Such a governmental objective can be brought about through pre-commitment of subsidy provisions. A production (export) subsidy and an economy-wide research and development subsidy are typical examples of such a policy. Pre-commitments by the government enable the domestic exporting firm to play the strategic game as a Stackelberg leader rather than in a Nash fashion. Along the same line, the strategic environmental policy literature addresses the issue whether an "over-lax" environmental policy can be used as an alternative to providing subsidies to domestic exporting firms (Conrad, 1993). Unlike other domestic subsidies, however, over-lax environmental regulations also entail a social cost in terms of increased pollution (Rauscher, 1994, p. 832).

The case of oligopoly is interesting because it allows for strategic policy making. The work on optimal environmental policy in an oligopolistic world market has mainly been dealt with in a partial equilibrium framework. Barrett (1994) and Kennedy (1994) consider two firms, 
one domestic and the other foreign, competing on a third market. They show that in the case of Cournot competition, welfare maximization indeed dictates an "over-lax" environmental policy in the sense that the home firm pays less than the Pigouvian tax corresponding to the marginal damage of pollution. This result is reversed in the case of Bertrand competition. Rauscher (1994), and Elbers and Withagen (2002a, b) consider the issue in a general equilibrium setting. Their analyses go beyond the question whether or not environmental policy yields Pigouvian outcomes, by considering discrimination in the stringency of environmental policy between the domestic and the export sectors. Elbers and Withagen $(2002 \mathrm{a}, \mathrm{b})$ show that the partial equilibrium recommendation may not hold in the case of a general equilibrium approach.

The policy context of the current paper is different from the studies mentioned above. Instead of incorporating emissions in the welfare function because of the damage they inflict, we introduce an upper bound on emissions. The government derives the demand for emissions from the firms' cost functions and fixes emission taxes by targeting emission levels corresponding to the upper bound of the emissions use. Attempts to increase production of the export sector by lowering the tax in this sector should then necessarily be accompanied by a rise in the tax imposed on the domestic sector. This implies that, unlike in the models discussed above, a mere trade-off between additional emissions and additional welfare is absent because of the binding resource constraint. Consequently, the export sector cannot be considered in isolation and a general equilibrium approach is in order, contrary to the "general practice in the [Brander-Spencer] literature" (Bhagwati et al., 1998, p. 382).

The change in policy context is inspired by real-world developments, such as the case of countries trying to meet agreements like the Kyoto Protocol. The protocol determines concrete targets of carbon dioxide emission reduction (Article 3, United Nations Conventions on Climate Change). In such a policy setting, ecological dumping or preferential treatment of the exposed sector is a pivotal and relevant issue. For example, in The Netherlands a government advisory committee recently recommended the introduction of a hybrid system of tradable permits that is more favorable to exposed industries than to sheltered industries. The main result of the present investigation is that we can identify a class of economies where ecological dumping, in the sense of imposing a relatively lax environmental policy on the exposed sector, is sub-optimal from the welfare perspective of the country under consideration as well as 
from the point of view of profitability of the exposed sector. What we do not treat in this paper is international permit trade. Although this is a relevant topic, particularly in the context of $\mathrm{CO}_{2}$ emissions reduction, we would like to focus on differential treatment of sectors within an economy in this paper. As a result, we do not discuss strategic behavior on an international permits market.

The remainder of this paper is organized as follows. In Sect. 2, we introduce our basic model with features largely identical to the models discussed above. We also derive some preliminary results on perfect competition and the large country case. Section 3 investigates the issue in an oligopolistic structure of the world market. Section 4 concludes.

\section{The Model and Preliminary Results}

\subsection{Introduction}

In this section, we outline the general equilibrium model that will serve as a benchmark to compare the case of emission limits to the case usually treated in the literature where pollution enters the social welfare function. We also provide results for perfect competition and the "large country" case.

\subsection{The Model}

The economy produces two types of final commodities with two inputs. The first final commodity is consumed and produced only domestically. Production takes place in the so-called sheltered sector consisting of many price-taking firms. Hence, we do not account for imperfect competition on the domestic market. The aggregate production function is denoted by $F_{1}$ and has capital, $k_{1}$, and raw material, $y_{1}$, as inputs. Domestic consumption is denoted by $c_{1}$. A second class of $n(n \geq 1)$ varieties of commodities is produced in the exposed sector. Aggregate production of variety $i(i=1,2, \ldots n)$ is described by a neoclassical production function $F_{2}^{i}$, which has capital, $k_{2}^{i}$, and raw material, $y_{2}^{i}$, as arguments. Following the strategic trade literature we assume that these commodities are exported only $\left(x_{2}^{i}\right)$, and not consumed domestically. The third consumer commodity is imported, and its consumption is denoted by $c_{3}$. This commodity serves as the numéraire. This rather rigid partitioning of commodities is common in this literature. In case of perfect 
competition on the home market the results of this paper will not be affected by allowing for domestic consumption of the good produced in the sheltered sector. Alternatively, it has to be taken into account that the additional externality caused by imperfect competition on the home market calls for an appropriate policy instrument. ${ }^{1}$

Capital is mobile domestically, but immobile internationally. ${ }^{2}$ The economy's endowment of capital is $\bar{k}$. The rate of return on capital is denoted $r$. Raw material can be conceived of as energy, possibly from fossil fuel, where exhaustibility of the resource is neglected. Pollution is normalized such that using one unit of the raw material entails one unit of polluting emission. To keep the analysis simple we abstract from abatement. Due to international environmental agreements, the economy is faced with an upper bound $\bar{y}$ on aggregate emissions. Regarding the market price of raw material various assumptions can be made. One may assume that the market price is zero and producers just have to pay an emissions tax $\tau$, possibly differentiated across the sectors of the economy. The assumption of a zero price is mathematically convenient. If the raw material is of domestic origin, the assumption is innocuous, because it can then be argued that supply is inelastic at a level that is higher than the total allowed emissions. If the raw material is imported, it implies a rather simple balance of payments condition, but then the assumption of a zero market price is more difficult to defend. The approach we choose is to assume that the world market price of the raw material is fixed, that the country under consideration is importing all it needs, and that in the absence of a cap on emissions the economy will import more than this cap. This implies that national expenditures are fixed, and they will be denoted by the constant $\chi \geq 0$.

Utility of the representative consumer is represented by a neoclassical utility function $U\left(c_{1}, c_{3}\right)$, implying that preferences involve consumption

1 For a discussion of how to deal with pollution in the case of imperfect competition on the domestic output market, see Barnett (1980), Baumol and Oates (1988), Shaffer (1995), and Simpson (1995).

2 The immobile factor is referred to as capital, but if applicable one can also think of labor as the immobile factor. Gordon and Bovenberg (1996) single out asymmetric information between domestic investors and foreign investors as the most important factor explaining the empirical evidence on international immobility of capital. They argue that foreign investors are at a disadvantage due to lack of information regarding issues such as purchase prices of assets and inputs, output markets, and future government policies. 
only. Pollution does not play a role because of the assumption that the emissions constraint is binding. Hence, the case where social welfare increases by adopting a lower than allowed pollution level is excluded. One can argue that the international agreement imposes a Pareto efficient distribution of pollution over its signatories, which entails lower emissions than in the Nash equilibrium.

\subsection{First-best in Perfect Competition and "Large" Country Case}

The first-best optimum in the economy is the allocation that maximizes social welfare,

$$
\begin{gathered}
U\left(c_{1}, c_{3}\right), \quad \text { subject to: } \\
c_{1}=F_{1}\left(k_{1}, y_{1}\right), \\
x_{2}^{i}=F_{2}^{i}\left(k_{2}^{i}, y_{2}^{i}\right), \quad(i=1,2, \ldots, n), \\
c_{3}+\chi=\sum_{i=1}^{n} p_{2}^{i}\left(x_{2}^{i}\right) x_{2}^{i}, \\
k_{1}+\sum_{i=1}^{n} k_{2}^{i}=\bar{k}, \\
y_{1}+\sum_{i=1}^{n} y_{2}^{i}=\bar{y},
\end{gathered}
$$

where $p_{2}^{i}=p_{2}^{i}\left(x_{2}^{i}\right)(i=1,2, \ldots, n)$ denote the inverse world demand functions. ${ }^{3}$ Note that Eq. (2.3) implies equilibrium on the current account: the value of the imported consumer commodity plus the expenditures on raw material equals the value of exported commodities. The Lagrangian of the problem reads as:

3 In the next section, where we discuss oligopoly, these functions will also depend on supply by foreign countries. 


$$
\begin{aligned}
L= & U\left(c_{1}, c_{3}\right)+\mu_{1}\left[F_{1}\left(k_{1}, y_{1}\right)-c_{1}\right]+\sum_{i=1}^{n} \mu_{2}^{i}\left[F_{2}^{i}\left(k_{2}^{i}, y_{2}^{i}\right)-x_{2}^{i}\left(p_{2}^{i}\right)\right] \\
& +\mu_{3}\left[\sum_{i=1}^{n} p_{2}^{i} x_{2}^{i}\left(p_{2}^{i}\right)-c_{3}-\chi\right]+\bar{r}\left[\bar{k}-k_{1}-\sum_{i=1}^{n} k_{2}^{i}\right] \\
& +\bar{\tau}\left[\bar{y}-y_{1}-\sum_{i=1}^{n} y_{2}^{i}\right] .
\end{aligned}
$$

Assuming an interior solution we find as necessary conditions:

$$
\begin{gathered}
\frac{\partial U}{\partial c_{1}}=\mu_{1}, \quad \frac{\partial U}{\partial c_{3}}=\mu_{3}, \\
\mu_{1} \frac{\partial F_{1}}{\partial k_{1}}=\bar{r}, \quad \mu_{1} \frac{\partial F_{1}}{\partial y_{1}}=\bar{\tau}, \\
\mu_{2}^{i} \frac{\partial F_{2}^{i}}{\partial k_{2}^{i}}=\bar{r}, \quad \mu_{2}^{i} \frac{\partial F_{2}^{i}}{\partial z_{2}^{i}}=\bar{\tau}, \quad i=1,2, \ldots, n, \\
-\mu_{2}^{i} \frac{d x_{2}^{i}}{d p_{2}^{i}}+\mu_{3}\left[x_{2}^{i}\left(p_{2}^{i}\right)+p_{2}^{i} \frac{d x_{2}^{i}}{d p_{2}^{i}}\right]=0, i=1,2, \ldots, n .
\end{gathered}
$$

\subsection{Implementation with Trade Policy}

In this setting, many results regarding the implementation of the first-best optimum in a decentralized economy are straightforward modifications of earlier work by, for instance, Hoel (1996) and Rauscher (1997), and they have become standard inferences in the theory of international trade (see, e.g., Dixit, 1985). We will briefly describe the main outcomes. In order to comply with the international norm given by $\bar{y}$, the government levies emission taxes $\tau_{1}$ and $\tau_{2}^{i}(i=1,2, \ldots, n)$. ${ }^{4}$ Tax revenues are recycled to consumers in a lump sum fashion. Alternatively, the government installs a system of tradable emissions permits. Such a system is uniform if trade is allowed among all domestic sectors, including the sheltered sector. The

4 For the sake of brevity of notation and without loss of generality the given world market price of energy is included in the $\tau$ 's. 
system is differentiated if individual sectors have their own system, with trade limited to those firms belonging to the individual sectors. In the present context, the policy instruments are equivalent: taxes can achieve the optimal emission levels or one can set the optimal amount of permits (possibly differentiated across sectors) and then leave it to the market to get the "right" price. We will therefore in the remainder of this paper only refer to taxes.

A few definitions are in order. We make a distinction between market power of the country on the one hand and of individual firms on the other. The country is large with respect to variety $i$ if, in the first-best optimum, the price elasticity of demand for variety $i$ is finite. Otherwise the country is small with respect to the variety. As a consequence, all individual firms producing a variety for which the economy is small can be aggregated and described as a representative competitive firm. Within the class of commodities for which the country is large, a further distinction can be made. In some of these "large" sectors a continuum of competitive firms is active, allowing for aggregation into a single representative firm as well. Each of the other "large" sectors will be assumed to consist of a single firm, exploiting its market power on the world market. The oligopoly case is studied in the next section. Define:

$$
\begin{gathered}
t^{i}=-\frac{1}{\hat{\varepsilon}_{2}^{i}}, \quad p_{1}=\frac{\hat{\mu}_{1}}{\hat{\mu}_{3}}, \quad q_{2}^{i}=\frac{\hat{\mu}_{2}^{i}}{\hat{\mu}_{3}}=p_{2}^{i}\left(1-t^{i}\right), \quad(i=1,2, \ldots, n), \\
p_{3}=1, \quad \tau=\tau_{1}=\tau_{2}^{i}=\frac{\bar{\tau}}{\hat{\mu}_{3}}, \quad(i=1,2, \ldots, n), \quad r=\frac{\hat{\bar{r}}}{\hat{\mu}_{3}},
\end{gathered}
$$

where hats denote the first-best outcomes, and $\hat{\varepsilon}_{2}^{i}$ is the price elasticity of world market demand for the second commodity which, evaluated at the optimum, is smaller than minus unity. Due to the concavity/convexity assumptions for the functions involved, the necessary conditions corresponding with the first-best social optimum are also sufficient. Observe the following.

(i) The pair $\left(\hat{k}_{1}, \hat{y}_{1}\right)$ maximizes profits $p_{1} F_{1}\left(k_{1}, z_{1}\right)-r k_{1}-\tau y_{1}$ of (aggregate) firm 1. This is the case because in the first-best solution the pair maximizes: 


$$
\hat{\mu}_{3}\left[\frac{\hat{\mu}_{1}}{\hat{\mu}_{3}} F_{1}\left(k_{1}, y_{1}\right)-\frac{\hat{\bar{r}}}{\hat{\mu}_{3}} k_{1}-\frac{\hat{\tau}}{\hat{\mu}_{3}} y_{1}\right] .
$$

(ii) For the same reason $\left(\hat{k}_{2}^{i}, \hat{y}_{2}^{i}\right)$ maximizes profits $p_{2}^{i} F_{2}^{i}\left(k_{2}^{i}, y_{2}^{i}\right)$ $-r k_{2}^{i}-\tau y_{2}^{i}$ of the (aggregate) firm of exporting sector $i$ for which the country is small.

(iii) Also $\left(\hat{k}_{2}^{i}, \hat{y}_{2}^{i}\right)$ maximizes profits $q_{2}^{i} F_{2}^{i}\left(k_{2}^{i}, y_{2}^{i}\right)-r k_{2}^{i}-\tau y_{2}^{i}$ of the (aggregate) firm of the competitive exporting sector $i$ for which the country is large.

(iv) The triple $\left(p_{2}^{i}, k_{2}^{i}, y_{2}^{i}\right)$ maximizes $p_{2}^{i} x_{2}^{i}\left(p_{2}^{i}\right)-r k_{2}^{i}-\tau y_{2}^{i}$ subject to $F_{2}^{i}\left(k_{2}^{i}, y_{2}^{i}\right)=x_{2}^{i}\left(p_{2}^{i}\right)$ for each exporting sector $i$ with a single supplier, exploiting its market power.

(v) The pair $\left(\hat{c}_{1}, \hat{c}_{3}\right)$ maximizes $U\left(c_{1}, c_{3}\right)$ subject to:

$$
p_{1} c_{1}+p_{3} c_{3}=p_{1} F_{1}+\sum_{i=1}^{n} q_{2}^{i} F_{2}^{i}+T-\chi
$$

where $T$ denotes recycled export tariff revenues.

(vi) Finally, all markets clear at the proposed prices.

Hence, we can state:

Proposition 1: The first-best optimum can be implemented in a decentralized economy by:

(i) imposing a uniform emission tax; and

(ii) imposing export taxes on the firms in sectors where the economy is "large" but where the individual firms do not exploit this.

The main implication of Proposition 1 is that there is no need to differentiate environmental policy across sectors if the country is small on all world markets or if its individual firms exploit their market power on the world market, or if the government can levy an export tax on "large" but competitive sectors. This result is similar to the result obtained when pollution is affecting social welfare directly. 


\subsection{Implementation without Trade Policy}

If export taxes are not allowed, due to for instance regulations of the World Trade Organization (WTO), the first-best optimum cannot be reached and we should look for a second-best solution.

Proposition 2: Suppose trade policy is not a viable option. Then in an optimum, higher emission taxes than for the sheltered sector should be imposed on those competitive exposed sectors for which the country is large.

Proof: It holds that:

$$
\begin{aligned}
d W= & \frac{\partial U}{\partial c_{1}} d c_{1}+\frac{\partial U}{\partial c_{3}} d c_{3}=\frac{\partial U}{\partial c_{3}}\left[p_{1} d c_{1}+d c_{3}\right] \\
= & \frac{\partial U}{\partial c_{3}}\left[p_{1}\left\{\frac{\partial F_{1}}{\partial k_{1}} d k_{1}+\frac{\partial F_{1}}{\partial y_{1}} d y_{1}\right\}\right. \\
& \left.+\sum_{i=1}^{n} p_{2}^{i}\left\{\frac{\partial F_{2}^{i}}{\partial k_{2}^{i}} d k_{2}^{i}+\frac{\partial F_{2}^{i}}{\partial y_{2}^{i}} d y_{2}^{i}+x_{2}^{i}\left(p_{2}^{i}\right) d p_{2}^{i}\right\}\right] .
\end{aligned}
$$

For all sectors $i$ for which the country is a price taker we have $d p_{2}^{i}=0$ and $p_{2}^{i} \frac{\partial F_{2}^{i}}{\partial k_{2}^{i}}=r, p_{2}^{i} \frac{\partial F_{2}^{i}}{\partial y_{2}^{i}}=\tau_{2}^{i}$ (see observation ii). For all competitive sectors $i$ for which the country is large we have $p_{2}^{i} \frac{\partial F_{2}^{i}}{\partial k_{2}^{i}}=r, p_{2}^{i} \frac{\partial F_{2}^{i}}{\partial y_{2}^{i}}=\tau_{2}^{i}$ (see observation iii). For all sectors that behave as large sectors by themselves we have $p_{2}^{i} \frac{\partial F_{2}^{i}}{\partial k_{2}^{i}}+p_{2}^{i} \frac{\partial F_{2}^{i}}{\partial y_{2}^{i}}+x_{2}^{i}\left(p_{2}^{i}\right) d p_{2}^{i}=r d k_{2}^{i}+\tau_{2}^{i} d y_{2}^{i}$ (see observation iv). Hence:

$$
d W=\frac{\partial U}{\partial c_{3}}\left[\tau_{1} d y_{1}+\sum_{i=1}^{n} \tau_{2}^{i} d y_{2}^{i}+\sum_{i \in C} x_{2}^{i} d p_{2}^{i}\right],
$$

where $C$ denotes the set of varieties in which the country as a whole is large, but for which the individual firms are competitive. If emission taxes would be undifferentiated it follows that:

$$
d W=\frac{\partial U}{\partial c_{3}} \sum_{i \in C} x_{2}^{i} d p_{2}^{i}
$$


Hence, welfare is marginally increased if the tax policy improves the terms of trade. This can be achieved by levying higher emissions taxes on the competitive exposed sectors than on the sheltered sectors.

The intuition behind this result is simple. Trade policy would increase the terms of trade, and an emission tax is effectively doing the same.

\section{Oligopoly}

\subsection{Introduction}

The preceding section considered the issue of strategic environmental policy in the presence of perfect competition and monopolistic market structures. In the present section, we focus on oligopoly, and allow for strategic interaction among firms as well as among governments, in a two-country setting. We use the superscripts $f$ and $h$ to refer to the foreign and home country, respectively, and consider the case of a single domestic producer $(n=1)$ of the exportable acting as a duopolist on the world market. The inverse demand function reads as $p_{2}\left(x_{2}\right)=p_{2}\left(x_{2}^{h}+x_{2}^{f}\right)$.

\subsection{Nash Equilibrium}

Following the same approach as in Proposition 2, totally differentiating the home country's welfare function, while omitting the superscript $h$, yields:

$$
d W=\frac{\partial U}{\partial c_{3}}\left[\tau_{1} d y_{1}+\tau_{2} d y_{2}+x_{2}^{h} \frac{d p_{2}}{d\left[x_{2}^{h}+x_{2}^{f}\right]} d x_{2}^{f}\right] .
$$

We can then readily establish:

Proposition 3: Suppose the home country's policy maker takes foreign supply as given. Then it is optimal to set equal emissions taxes or to install a uniform system of tradable emissions permits.

Proof: If $d x_{2}^{f}=0$ then $\tau_{1}=\tau_{2}$, which, together with $d y_{1}+d y_{2}=$ $d \bar{y}=0$, yields $d W=0$.

Consequently, if given the international environmental agreement the governments play a simultaneous move Nash game, differential treatment of the two sectors is sub-optimal. The terms of trade effect is already 
incorporated by the Nash-Cournot duopolists. However, matters change if by manipulating the domestic emissions tax rates foreign supply can be affected. In that case, starting from equal taxes, a policy that reduces foreign supply is beneficial, as can be seen from Eq. (3.1).

\subsection{Stackelberg Equilibrium}

We turn now to the case where the foreign country is a Stackelberg follower, and the home country is the Stackelberg leader. In the game, there are essentially four players, the two oligopolistic firms and the two governments. The individual firms are Cournot-Nash players on the world product market and take their rival's supply as given. One way to model the game at the policy makers' level is to assume that the foreign government, the follower, takes the tax rates set by the home government as given, and maximizes its own welfare given these taxes. However, this complicates matters for the following reason. The tax structure in the home country does not completely determine the home country's supply on the world market, because it is also affected by the supply of the foreign firm, which is subject to taxation in the foreign country. Therefore, with this setup the foreign country can still have a considerable indirect effect on supply by the home firm, which we would like to exclude. In order to overcome this complication we assume that the foreign government only observes world market supply by the home firm, takes this as given, and subsequently determines its own optimal tax structure. As a result, for any given $x_{2}^{h}$ the foreign government sets uniform emissions taxes that maximize social welfare. These taxes then also generate foreign supply. Subsequently, the home government takes the overall reaction function of the foreign country into account in determining its own optimal taxes. Formally, an equilibrium of the game is a set of domestic and foreign tax rates and supply to the world market such that:

(a) given the home world market supply, the foreign country sets the emissions taxes optimally so as to maximize its social welfare, and

(b) taking foreign supply as a function of home supply as given, the home country maximizes social welfare by setting home emissions taxes.

For the outcome of the game, the slope of the foreign reaction function is crucial. If the foreign reaction function is upward sloping, then, starting 
from a situation of undifferentiated emission taxes, the home government wants to decrease its own supply to the world market, implying a welfare increase; see (3.1). The welfare improvement is then accomplished by increasing the tax rate applying to the exposed sector. If the foreign reaction function is downward sloping, a decrease of the tax rate imposed on the exposed sector is in order. The issue is closely related to the strategic trade policy literature (see Brander and Spencer, 1985; Helpman and Krugman, 1985), where the question whether the outputs of the oligopolists are strategic complements or strategic substitutes is crucial for policy. In two papers, Collie and de Meza (1986; 2003) address this problem in a partial equilibrium model, but not in the context of a general equilibrium environmental policy setting. They show that with a constant price elasticity demand function, the reaction functions in a Nash equilibrium are downward sloping if and only if demand is elastic. However, we show below that in our general equilibrium setting the sign may be reversed. To do so, we employ the following specifications:

$$
\begin{gathered}
U\left(c_{1}, c_{3}\right)=\ln c_{1}+\ln c_{3}, \\
F_{1}\left(k_{1}, y_{1}\right)=k_{1}^{\alpha} y_{1}^{1-\alpha}, \quad 0<\alpha<1, \\
F_{2}\left(k_{2}, y_{2}\right)=k_{2}^{\beta} y_{2}^{1-\beta}, \quad 0<\beta<1, \\
p_{2}\left(x_{2}+x_{2}^{f}\right)=\left(x_{2}+x_{2}^{f}\right)^{1 / \varepsilon}, \quad \varepsilon<-1 .
\end{gathered}
$$

Lemma 1: Suppose preferences, world demand, and technology are given by (3.2)-(3.5). Suppose that the foreign economy takes $x_{2}^{h}$ as given and finds itself in a general equilibrium. Then, $\frac{d x_{2}^{f}}{d x_{2}^{h}} \geq 0$.

Proof: See the Appendix.

With the aid of Lemma 1 we can now state and prove:

Proposition 4: Suppose preferences, world demand, and technology are given by (3.2)-(3.5). Suppose that the foreign economy takes $x_{2}^{h}$ as given and finds itself in a general equilibrium. Let the home country act as a Stackelberg leader. Then $\tau_{2}^{h} \geq \tau_{1}^{h}$. 
Proof: Consider (3.1). Taking into account that $d y_{1}=-d y_{2}$ and omitting the suffix $h$, we have:

$$
d W=\frac{\partial U}{\partial c_{3}}\left[\left[\tau_{1}-\tau_{2}\right] d y_{1}+x_{2}^{h} \frac{d p_{2}}{d\left[x_{2}^{h}+x_{2}^{f}\right]} d x_{2}^{f}\right] .
$$

Starting from $\tau_{1}=\tau_{2}$, we see that welfare increases if $x_{2}^{f}$ decreases, ceteris paribus. Therefore, in view of Lemma 1, policy should lead to a lower $x_{2}^{f}$. This is achieved by increasing $\tau_{2}$ and decreasing $\tau_{1}$, which also makes the first term between brackets positive.

The proposition yields the important insight that for the class of specifications under consideration, the exposed sector needs to be taxed more heavily than the sheltered sector if the home country is a Stackelberg leader. Although the optimality of this policy has not been assessed for other classes than the one considered here, the relevance of the result is that it runs counter to what is commonly advocated in policy circles.

\subsection{Political Economy Considerations}

In view of political economy aspects such as rent seeking and lobbying, which may prevent the feasibility or the acceptability of the new tax policy, we analyze its effect on the profitability of the exposed sector. This is, however, not a direct test of the Porter hypothesis, which claims that stringent environmental policy increases profitability. In our model research and development do not play a role, whereas innovation offsets are pertinent to the Porter hypothesis. Following Palmer et al. (1995), however, one may argue that an increased competitive position of domestic exporters as a consequence of environmental policy is in line with the Porter hypothesis.

The unit cost function of the exposed sector reads:

$$
c_{2}\left(r, \tau_{2}\right)=\left(\frac{r}{\beta}\right)^{\beta}\left(\frac{\tau_{2}}{1-\beta}\right)^{1-\beta}
$$

Profit maximization boils down to the maximization of:

$$
\Pi_{2}\left(x_{2}^{h}\right)=p\left(x_{2}^{h}+x_{2}^{f}\right) x_{2}^{h}-c\left(r, \tau_{2}\right) x_{2}^{h},
$$


with foreign supply given. With the inverse demand function (3.5) and using the first-order necessary condition for profit maximization we have:

$$
\Pi_{2}\left(x_{2}^{h}\right)=\frac{\left(x_{2}^{h}\right)^{2}}{-\varepsilon\left[x_{2}^{h}+x_{2}^{f}\right]^{1-1 / \varepsilon}}=\frac{\left(x_{2}^{h}\right)^{1+1 / \varepsilon}}{-\varepsilon\left[1+\frac{x_{2}^{f}}{x_{2}^{h}}\right]^{1-1 / \varepsilon}} .
$$

Therefore, in comparing the Nash and the Stackelberg tax regimes, profitability is enhanced if domestic output increases (since $\varepsilon<-1$ ), or if foreign supply decreases relative to home supply. Indeed, home supply of the traded commodity may increase compared to the Nash equilibrium. Obviously, this is not the case when the two equilibria are close to each other, because in that case, by virtue of Lemma 1, the Stackelberg leader should increase the emission tax on the exposed sector. However, when the economies differ considerably, the Nash equilibrium tax rate is no longer necessarily between the two Stackelberg tax rates.

Table 1 provides a numerical illustration of this result, using the following base parameters: initial capital endowment is $\bar{k}^{h}=10$; the upper limits on emissions are $\bar{y}^{h}=6$ and $\bar{y}^{f}=20$; the price elasticity of world demand $\varepsilon$ equals -2 , and the production elasticities of capital are $\alpha=\beta=0.75$ for both countries. In Table 1 , the initial capital endowment of the foreign country $\bar{k}^{f}$ runs from 10 to 24 .

As expected, when the economies are similar with regard to their initial capital the Nash tax rate is between the Stackelberg tax rates for the sheltered and exposed sectors. Moreover, the exposed sector suffers from the new tax regime in terms of profitability. However, with an increasing difference in capital endowments, the exposed sector benefits

Table 1. A comparison of Nash-Cournot and Stackelberg equilibria

\begin{tabular}{|c|c|c|c|c|c|c|c|c|c|}
\hline \multicolumn{5}{|c|}{ Nash-Cournot } & \multicolumn{5}{|c|}{ Stackelberg } \\
\hline $\bar{k}^{f}$ & $\tau$ & $x_{2}^{h}$ & $x_{2}^{f}$ & $\Pi_{2}$ & $\tau_{1}^{h}$ & $\tau_{2}^{h}$ & $x_{2}^{h}$ & $x_{2}^{f}$ & $\Pi_{2}$ \\
\hline 24 & 0.1283 & 0.1991 & 7.7698 & 0.0009 & 0.0840 & 0.0871 & 4.0151 & 9.0628 & 0.1704 \\
\hline 22 & 0.1185 & 0.9188 & 7.6546 & 0.0168 & 0.0852 & 0.0883 & 3.9997 & 8.5373 & 0.1802 \\
\hline 20 & 0.1087 & 1.7987 & 7.4762 & 0.0573 & 0.0865 & 0.0896 & 3.9823 & 7.9968 & 0.1913 \\
\hline 18 & 0.1003 & 2.7363 & 7.1963 & 0.1196 & 0.0879 & 0.0910 & 3.9627 & 7.4392 & 0.2039 \\
\hline 16 & 0.0951 & 3.4707 & 6.7829 & 0.1834 & 0.0894 & 0.0925 & 3.9402 & 6.8620 & 0.2186 \\
\hline 14 & 0.0937 & 3.8169 & 6.2471 & 0.2282 & 0.0910 & 0.0942 & 3.9140 & 6.2615 & 0.2360 \\
\hline 12 & 0.0946 & 3.8872 & 5.6338 & 0.2572 & 0.0929 & 0.0959 & 3.8828 & 5.6332 & 0.2568 \\
\hline 10 & 0.0964 & 3.8607 & 4.9722 & 0.2839 & 0.0949 & 0.0979 & 3.8450 & 4.9704 & 0.2824 \\
\hline
\end{tabular}


more from the higher tax rate, relative to the tax rate of the sheltered sector. Although the exposed sector pays more taxes than the sheltered sector, the tax rate is considerably smaller than in the Nash equilibrium. Therefore, being a Stackelberg leader is not only welfare enhancing at the country level, but it also increases profitability in the sector that is subject to the more stringent environmental policy. However, the table also shows that the profit differential is positive when the foreign country is relatively well endowed with both capital and allowable emissions. In such circumstances it is more difficult to justify the Stackelberg leadership for the home country, at least within the present model.

\section{Conclusions}

This paper revisits the issue of ecological dumping. The main question is whether governments have reason to give preferential treatment to their exposed sector. The novelty of our approach is that we consider several world market structures, with an emphasis on oligopoly, in a general equilibrium setting. Moreover, rather than incorporating emissions in the social welfare function, we assume the implementation of a policy that puts a mandatory upper bound on aggregate emissions. This policy constellation is realistic given that many countries are currently trying to meet restrictions imposed by agreements such as the Kyoto Protocol.

The cases of perfect competition and of a large country produce the expected results. Differential treatment is unwarranted if perfect competition prevails. When the country under consideration is large and conventional trade policy instruments cannot be used, the exposed sector should be taxed more heavily than the domestic sector, except when this sector can reap the terms of trade benefits by itself. The more interesting case, however, is oligopoly. It has been shown that in a simultaneous move Nash equilibrium of the tax game played by two governments, equilibrium emissions taxes do not differ between sectors. However, we show that in a Stackelberg equilibrium the leader may find it optimal to tax the exposed sector more heavily than the sheltered sector. We illustrate this theoretical result in an example, employing Cobb-Douglas type specifications for the functions involved.

Our theoretical results have important implications for the policy debates on globalization and the environment, and the issue of harmonization of environmental policies across countries. Our results shed 
new light on the frequently cited tension between trade and environmental policy objectives by suggesting that fear of ecological dumping can hardly be substantiated by means of standard neoclassical theory. Obviously, in the real world matters are more complicated than we can currently capture in theoretical microeconomic models. Specifically, the assumption of governments behaving as strict social-welfare maximizing agents aiming to design and implement environmental policies in a socially optimal fashion is open to discussion and can be modified. It is nowadays customary to think of governments as policy brokers bringing together different interest groups with conflicting stakes in policy outcomes. Strictly speaking, it is therefore too early to completely rule out the possibility that policies of ecological dumping can be justified on the basis of social optimality grounds. However, it is equally implausible to expect the game of interest groups competing for policy influence to end up by necessity in a situation where proponents of eco-dumping will unequivocally dominate the game.

There are several interesting avenues for further research. One such avenue ties on to a less desirable characteristic of our approach where the information the Stackelberg leader needs in order to design an optimal policy is huge. Another highly relevant avenue concerns the real-world situation where not all countries are signatories. Overall, our results suggest the prevalence of a strong link between the design of international environmental agreements and the design of policies with respect to the environment and trade. A closer future investigation of this link will be worthwhile, both from a theoretical and a policy perspective.

\section{Appendix}

Proof of Lemma 1: The foreign country takes supply by the home country as given. Therefore it imposes a uniform emissions tax (see Proposition 4). The system of general equilibrium conditions for the foreign country is given by the following set of equations (explicit reference to foreign is omitted, when there is no danger of confusion):

$$
\frac{y_{1}}{k_{1}}=\frac{r}{\alpha} \frac{1-\alpha}{\tau}
$$




$$
\begin{gathered}
\frac{y_{2}}{k_{2}}=\frac{r}{\beta} \frac{1-\beta}{\tau}, \\
p_{1}=\left(\frac{r}{\alpha}\right)^{\alpha}\left(\frac{\tau}{1-\alpha}\right)^{1-\alpha}, \\
\left(x_{2}^{h}+x_{2}\right)^{1 / \varepsilon}\left[\begin{array}{c}
\left.1+\frac{x_{2}^{h}}{\varepsilon\left[x_{2}^{h}+x_{2}\right]}\right)^{1 / \varepsilon} \\
p_{2} \\
x^{\prime}
\end{array}\right)^{\beta}\left(\frac{\tau}{1-\beta}\right)^{1-\beta}, \\
y_{1}+y_{2}=\bar{y} \\
k_{1}+k_{2}=\bar{k} \\
x_{1} k_{1}^{\alpha} y_{1}^{1-\alpha}=k_{2}^{\beta} y_{2}^{1-\beta} .
\end{gathered}
$$

Equations (A.1) and (A.2) follow from cost minimization, and Eq. (A.3) follows from perfect competition in the sheltered sector. Equations (A.4) and (A.5) define profit maximization of the exposed sector, and Eqs. (A.6) and (A.7) are self-evident. Equation (A.8) follows from utility maximization and equilibrium on the current account: $p_{1} c_{1}=c_{3}=p_{2} x_{2}-\chi$. Finally, Eq. (A.9) is the production function of the exposed sector. The system is solved as follows. Using Eqs. (A.1), (A.2), (A.6) and (A.7) we obtain:

$$
k_{1}=-\frac{\alpha(1-\beta)}{\beta-\alpha} \bar{k}+\frac{\tau}{r} \frac{\alpha \beta}{\beta-\alpha} \bar{y}, \quad y_{1}=-\frac{r}{\tau} \frac{(1-\alpha)(1-\beta)}{\beta-\alpha} \bar{k}+\frac{\beta(1-\alpha)}{\beta-\alpha} \bar{y},
$$




$$
k_{2}=\frac{(1-\alpha) \beta}{\beta-\alpha} \bar{k}-\frac{\tau}{r} \frac{\alpha \beta}{\beta-\alpha} \bar{y}, \quad y_{2}=\frac{r}{\tau} \frac{(1-\alpha)(1-\beta)}{\beta-\alpha} \bar{k}-\frac{\alpha(1-\beta)}{\beta-\alpha} \bar{y} .
$$

Eliminating $p_{1}$ and $p_{2}$ by means of (A.3) and (A.4) and using (A.10), we obtain:

$$
\frac{\left(x_{2}+x_{2}^{h}\right)^{1 / \varepsilon} x_{2}}{r}-\chi=\frac{1}{\beta-\alpha}\left[\beta \frac{\tau}{r} \bar{y}-(1-\beta) \bar{k}\right] .
$$

Equation (A.5) can be rewritten as

$$
\left(\frac{\tau}{r}\right)^{1-\beta} \beta^{-\beta}(1-\beta)^{\beta-1} x_{2}=\frac{\left(x_{2}+x_{2}^{h}\right)^{1 / \varepsilon} x_{2}\left[+\frac{x_{2}}{\varepsilon\left[x_{2}+x_{2}^{h}\right]}\right]}{r} .
$$

The right-hand side of (A.5) is the unit cost function of the exposed firm. Using (A.11) again we thus have:

$$
\left(\frac{\tau}{r}\right)^{1-\beta} \beta^{-\beta}(1-\beta)^{\beta-1} x_{2}=\frac{1}{\beta-\alpha}\left[(1-\alpha) \bar{k}-\frac{\tau}{r} \alpha \bar{y}\right] .
$$

It follows from (A.12) and (A.13) that:

$$
\begin{aligned}
\left(\frac{\tau}{r}\right)^{1-\beta} \beta^{-\beta}(1-\beta)^{\beta-1} x_{2}= & \frac{1}{\beta-\alpha}\left[-(1-\beta) \bar{k}+\beta \frac{\tau}{r} \bar{y}+(\beta-\alpha) \chi\right] \\
& \times\left[1+\frac{1}{\varepsilon\left[1+x_{2}^{h} / x_{2}\right]}\right]
\end{aligned}
$$

and subsequently from (A.14) that:

$$
-\frac{(1-\alpha) \bar{k}-\alpha \frac{\tau}{r} \bar{y}}{(1-\beta) \bar{k}-\beta \frac{\tau}{r} \bar{y}-(\beta-\alpha) \chi}=1+\frac{1}{\varepsilon\left[1+x_{2}^{h} / x_{2}\right]} .
$$

Now suppose that the Lemma does not hold: $x_{2}$ increases and $x_{2}^{h}$ decreases, so that $x_{2}^{h} / x_{2}$ decreases. Then, first of all, the right-hand side of (A.16) decreases. Suppose $\beta>\alpha$, in which case $\tau / r$ decreases because of (A.14), and therefore, the left-hand side of (A.16) increases. This contradicts that the right-hand side of Eq. (A14) decreases. Suppose $\beta<\alpha$, in 
which case $\tau / r$ increases because of Eq. (A14), and therefore, the lefthand side of Eq. (A.16) increases, yielding a contradiction again.

\section{Acknowledgements}

The authors would like to thank Stéphane Lambrecht for valuable comments.

\section{References}

Barnett, A. (1980): "The Pigouvian Tax Rule under Monopoly." American Economic Review 70: 1037-41.

Barrett, S. (1994): "Strategic Environmental Policy and International Trade." Journal of Public Economics 54: 325-38.

Baumol, W., and Oates, W. (1988): The Theory of Environmental Policy. Cambridge, MA: Cambridge University Press.

Bhagwati, J., Panagariya, A., and Srinivasan, T. (1998): Lectures on International Trade. Cambridge, MA: MIT Press.

Brander, A., and Spencer, B. (1985): "Export Subsidies and International Market Share Rivalry." Journal of International Economics 18: 83-100.

Brander, J., and Taylor, S. (1997): "International Trade between Consumer and Conservationist Countries." Resource and Energy Economics 19: 267-97.

Collie, D., and de Meza, D. (1986): "Inadequacies of the Strategic Rationale of Export Subsidies." Economics Letters 22: 369-73.

Collie, D., and de Meza, D. (2003): "Comparative Advantage and the Pursuit of Strategic Trade Policy." Economics Letters 81: 279-83.

Conrad, K. (1993): "Taxes and Subsidies for Pollution-intensive Industries as Trade Policy." Journal of Environmental Economics and Management 25: $121-35$.

Copeland, B., and Taylor, S. (2003): International Trade and the Environment: Theory and Evidence. Princeton: Princeton University Press.

Dixit, A. (1985): "Tax Policy in Open Economies." In Handbook of Public Economics, edited by A. Auerbach and M. Feldstein. Amsterdam: NorthHolland, pp. 313-74.

Elbers, C., and Withagen, C. (2002a): "Environmental Regulation and International Trade: A General Equilibrium Approach." In Recent Advances in Environmental Economic, edited by J. List and A. de Zeeuw. Cheltenham: Edward Elgar, pp. 98-118.

Elbers, C., and Withagen, C. (2002b): "Environmental Policy and Bertrand Competition: A General Equilibrium Approach." In Equilibrium, Markets and Dynamics, edited by C. Hommes, R. Ramer and C. Withagen. Heidelberg: Springer, pp. 183-95.

Elbers, C., and Withagen, C. (2003): "Environmental Policy and International Trade: Are Policy Differentials Optimal?" In Environmental Policy in an International Perspective, edited by L. Marsiliani, M. Rauscher and C. Withagen. Dordrecht: Kluwer, pp. 173-91. 
Gordon, R., and Bovenberg, L. (1996) "Why Is Capital so Immobile Internationally? Possible Explanations and Implications for Capital Income Taxation." American Economic Review 86: 1057-75.

Helpman, E., and Krugman, P. (1985): Market Structure and Foreign Trade. Cambridge, MA: MIT Press.

Hoel, M. (1996): "Should a Carbon Tax Be Differentiated across Sectors?" Journal of Public Economics 59: 17-32.

Kennedy, P. (1994): "Equilibrium Pollution Taxes in Open Economies with Imperfect Competition." Journal of Environmental Economics and Management 27: 49-63.

Neary, P. (2006): "International Trade and the Environment: Theory and Policy Linkages." Environmental and Resource Economics 33: 95-118

Palmer, K., Oates, W., and Portney, P. (1995): “Tightening Environmental Standards: The Benefit-cost or the No-cost Paradigm?" The Journal of Economic Perspectives 9: 119-32.

Rauscher, M. (1994): “On Ecological Dumping.” Oxford Economic Papers 46: 822-40.

Rauscher, M. (1997): International Trade. Factor Movements, and the Environment. Oxford: Oxford University Press.

Schaffer, S. (1995): "Optimal Linear Taxation of Polluting Oligopolists." Journal of Regulatory Economics 7: 85-100.

Simpson, R. (1995): Optimal Pollution Taxation in a Cournot Duopoly." Environmental and Resource Economics 6: 359-69.

Spencer, B., and Brander, A. (1983): "International R\&D Rivalry and Industrial Strategy." Review of Economic Studies 50: 707-22.

Ulph, A. (1999): "Environment and Trade." In Principles of Environmental Economics II, edited by H. Folmer and L. Gabel. Cheltenham: Edward Elgar, pp. 479-528.

Addresses of authors: - C. A. Withagen, Department of Spatial Economics, Faculty of Economics, Vrije Universiteit, De Boelelaan 1105, 1081 HV Amsterdam, The Netherlands (e-mail: cwithagen@feweb.vu.nl.); - R. J. G. M. Florax, Department of Agricultural Economics, Purdue University, West Lafayette, USA and Department of Spatial Economics, Vrije Universiteit, Amsterdam, The Netherlands; - A. Mulatu, Economics, School of Social Sciences, University of Manchester, UK. 